\title{
Radiation-stimulated processes in silicon structures with contacts based on TiN
}

\author{
M.U. Nasyrov, A.B. Ataubaeva \\ Berdakh Karakalpak State University, 742000, Nukus, Uzbekistan, \\ Phone: +998 (61) 223-60-45; e-mail:a_akkumis@mail.ru
}

\begin{abstract}
The influence of irradiation on the structural properties of titanium nitride films deposited on silicon wafers has been considered. It has been shown that depending on the energy, fluence and type of irradiation ion, observed are the increase of accumulated damages with decreasing the grain size, the grain size reduction with increasing the fluence, the increase of dislocation density and microstrains.
\end{abstract}

Keywords: radiation-stimulated processes, silicon structure, titanium nitride film, contact.

Manuscript received 11.12.14; revised version received 10.04.15; accepted for publication 27.05.15; published online 08.06.15.

\section{Introduction}

Recently, the subject of intense researches is antidiffusion layers based on nanocrystalline refractory compounds that are used to enhance stability of the contacts to silicon devices. These contacts are used to create high-reliability devices for power and microwave electronics. Preparation and improvement of nanocrystalline materials for solid state microwave electronics is particularly important line of many researchers [1-16]. Due to high thermal, chemical and irradiation resistance, this class of nanomaterials can improve the quality and reliability of the contacts, and thus can be used as a diffusion barrier in the contact metallization [9-12]. In this work, presented has been the analysis of the results on the effect of radiation exposure (irradiation with $\mathrm{Ar}^{+}, \mathrm{V}^{+}$and $\mathrm{He}^{+}$ions) on the structural properties of the titanium nitride films used as diffusion barriers in silicon contact structures.

\section{Analysis of radiation-stimulated processes in $\mathrm{TiN}-\mathrm{Si}$ contacts}

Of interest to the technology of silicon integrated circuits are amorphous (nanostructured) titanium nitride films, electrical and structural properties of which are well known and described in the works by R.A. Andrievskii. For example, in $[17,18]$ their stability under radiation exposure were considered. Hand in hand with this, it was shown that, depending on the irradiation dose, in nanostructured materials the radiation-stimulated diffusion and mass transfer, recrystallization, and other relaxation phenomena can be observed. At the same time, changes in the properties of irradiated nanomaterials, which were caused by the influence of sized effects and interfaces, are poorly studied and require further investigation.

In the work [19], on irradiation with $\mathrm{He}^{+}$ions with the energy $12 \mathrm{keV}$, at fluence of $4 \cdot 10^{16} \mathrm{~cm}^{-2}$ at room temperature of the thin TiN films (the thickness is close to $100 \mathrm{~nm}$ ) having various grain sizes (8 to $100 \mathrm{~nm}$ ), there observed is accumulation of damages that are spatially distributed highly defect zone of 35-nm thickness at the bottom of TiN film. Fig. 1a shows TEM image of the initial TiN film deposited on Si substrate at $T=700{ }^{\circ} \mathrm{C}$ with a rather sharp interface $\mathrm{TiN} / \mathrm{Si}$ and grain size of $\sim 100 \mathrm{~nm}$. After irradiation with $\mathrm{He}^{+}$ions with the energy $12 \mathrm{keV}$, at the fluence $4 \cdot 10^{16} \mathrm{~cm}^{-2}$, the cleavage morphology of TiN/Si with an extended defect area in the TiN film is shown in Fig. $1 b$.

After increasing the energy of irradiation with $\mathrm{He}^{+}$ ions up to $35 \mathrm{keV}$, at fluence to $4 \cdot 10^{17} \mathrm{~cm}^{-2}$ the damage extends to the depth close to $200 \mathrm{~nm}$ into the Si substrate (Fig. 1c). In the TiN film deposited at $500{ }^{\circ} \mathrm{C}$ with the grain size $50 \mathrm{~nm}$, after irradiation at the fluence 
$1.0 \cdot 10^{16} \mathrm{~cm}^{-2}$, the damaged layer reaches $30 \mathrm{~nm}$ (Fig. 2a). In the TiN film with the grain size $30 \mathrm{~nm}$ deposited at $350{ }^{\circ} \mathrm{C}$, the defect area corresponds to $20 \mathrm{~nm}$ (Fig. 2b). Finally, the thickness of the damaged layer less than $5 \mathrm{~nm}$ is observed in the TiN film with the grain size $8 \mathrm{~nm}$ deposited at room temperature (Fig. 2c). Thus, from the above data it is seen that the thickness of the damaged layer decreases with decreasing the grain size, and the latter increases with increasing the deposition temperature.

The above studies show that the nanocrystalline TiN films with fine grains have better radiation resistance than materials with a large grain size. It is confirmed by the absence of amorphization on the boundaries of the crystallites with the size $8 \mathrm{~nm}$ (Fig. 3), pointing to the fact that the grain boundaries can act as effective diffusion sinks of radiation defects in accordance with [20].

The authors of [21] studied the effect of irradiation with $\mathrm{Ar}^{+}$ions possessing the energy $120 \mathrm{keV}$, fluences of $1 \cdot 10^{15} \mathrm{~cm}^{-2}$ and $1 \cdot 10^{16} \mathrm{~cm}^{-2}$ on the TiN film deposited onto $\mathrm{Si}$ at room temperature and at $150{ }^{\circ} \mathrm{C}$. X-ray analysis of the results showed that the titanium nitride was formed even in the deposition process at room temperature. It is confirmed by the presence of reflections TiN (111), (200), (220) and (311) (Fig. 4a). Here, it is seen that the reflections from TiN (220) are clearer pronounced than those from TiN (111), (200) and (311).

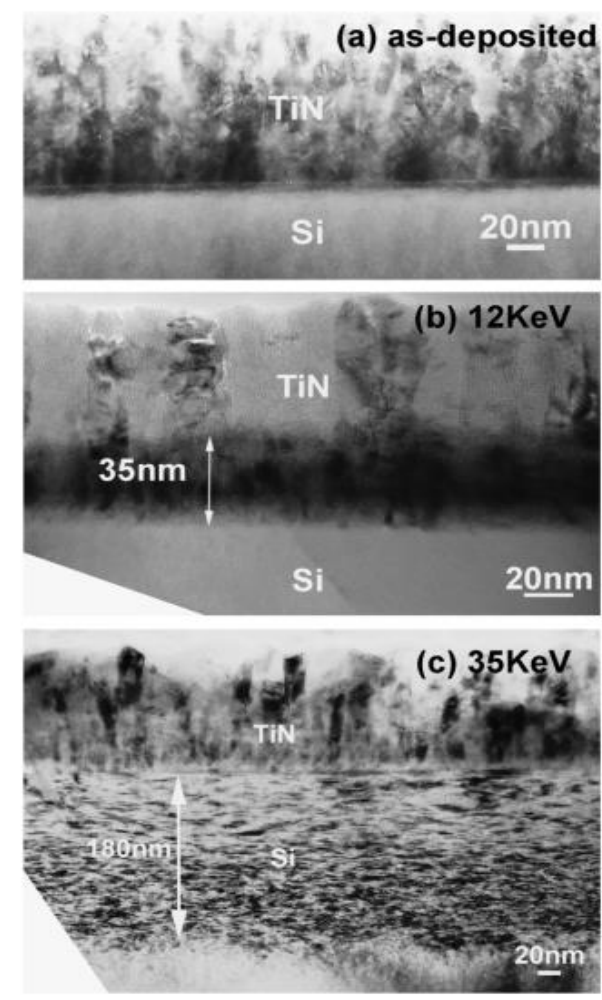

Fig. 1. TEM images of TiN films deposited (at $700{ }^{\circ} \mathrm{C}$ ) before (a) and after irradiation with $\mathrm{He}^{+}$ions $E=12 \mathrm{keV}$, fluence of $4 \cdot 10^{16} \mathrm{~cm}^{-2}$ (b) and $E=35 \mathrm{keV}$, fluence of $1 \cdot 10^{17} \mathrm{~cm}^{-2}$ (c) [19].
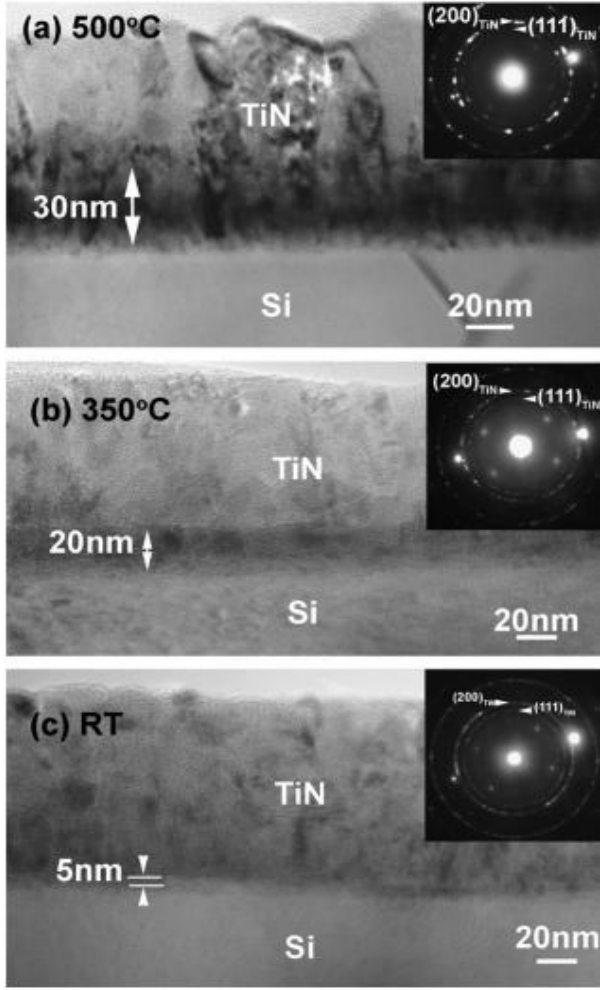

Fig. 2. TEM images of TiN films deposited at $500{ }^{\circ} \mathrm{C}$ (a), $350{ }^{\circ} \mathrm{C}(\mathrm{b})$, and at room temperature (c) and irradiated with $\mathrm{He}^{+}$ions $\left(E=12 \mathrm{keV}\right.$, fluence $\left.4 \cdot 10^{16} \mathrm{~cm}^{-2}\right)$ [19].

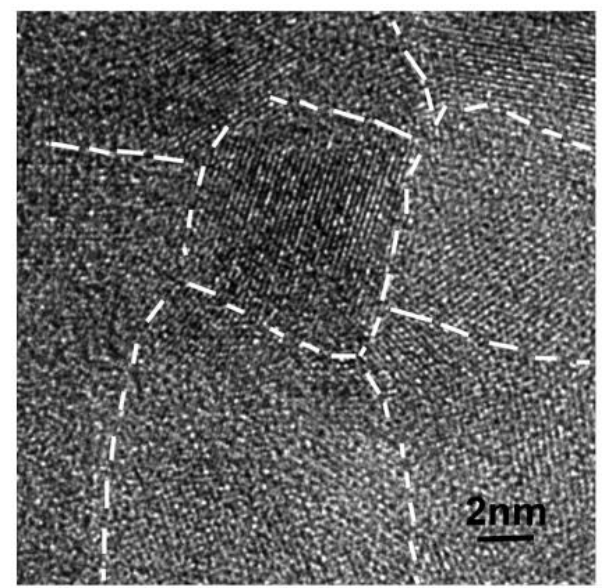

Fig. 3. High-resolution TEM image of the TiN films deposited at room temperature and irradiated with $\mathrm{He}^{+}$ions $(E=12 \mathrm{keV}$, fluence $4 \cdot 10^{16} \mathrm{~cm}^{-2}$ ) [19].

In the X-ray diffractogram of TiN films deposited at $150{ }^{\circ} \mathrm{C}$ and irradiated at fluences $10^{15}$ and $1 \cdot 10^{16} \mathrm{~cm}^{-2}$ (Figs. 5a to 5c), unlike those deposited at room temperature, the reflections from TiN (200) were not observed (Figs. 4a to 4c), which indicates the partial structuring of titanium nitride relative to the substrate. TEM results presented in [21] for these structures (Fig. 6) have shown that the $\mathrm{TiN}$ layer deposited at $150{ }^{\circ} \mathrm{C}$ is polycrystalline. It contains fine grains of different 
orientations (Figs. 6a to 6c). Irradiation at the fluence $1 \cdot 10^{16} \mathrm{~cm}^{-2}$ does not lead to dispersion of the diffraction rings, indicating the presence of an amorphous phase (insert in Fig. 6b), since in all the samples before and after irradiation there observed are reflections from $\operatorname{TiN}(200)$ (Figs. 6a to 6c) that are absent in the X-ray diffractogram (Figs. 5a to 5c). The authors [21] believe that amorphization is not the main reason for radiationinduced damages created in the field of thin TiN layers.

TiN layer deposited at $150{ }^{\circ} \mathrm{C}$ contains columnar crystallites with the diameter of columns close to $30 \mathrm{~nm}$ (Fig. 6a). After irradiation with $\mathrm{Ar}^{+}$ions at fluences up to $1 \cdot 10^{15} \mathrm{~cm}^{-2}$ on the TiN film surface, the damaged area of the thickness approximately $50 \mathrm{~nm}$ is formed (Fig. 6b). The authors [21] suggest that changes in the microstructure shown in Fig. 6 are associated with increasing migration, annihilation and agglomeration of defects stimulated by irradiation. This surface of TiN containing defects can act as a getter for defects located in the region below the surface. The results of the study of surface morphology of TiN layers [21] deposited at room temperature (Fig. 7a) have shown that the obtained $\mathrm{TiN}$ film is homogeneous. Its roughness after irradiation decreases from $\sim 0.5 \pm 0.03 \mathrm{~nm}$ down to $\sim 0.3 \pm 0.02 \mathrm{~nm}$ (Fig. 7b). Furthermore, the average grain size is reduced from $\sim 13 \pm 2 \mathrm{~nm}$ down to $\sim 7 \pm 0.02 \mathrm{~nm}$.

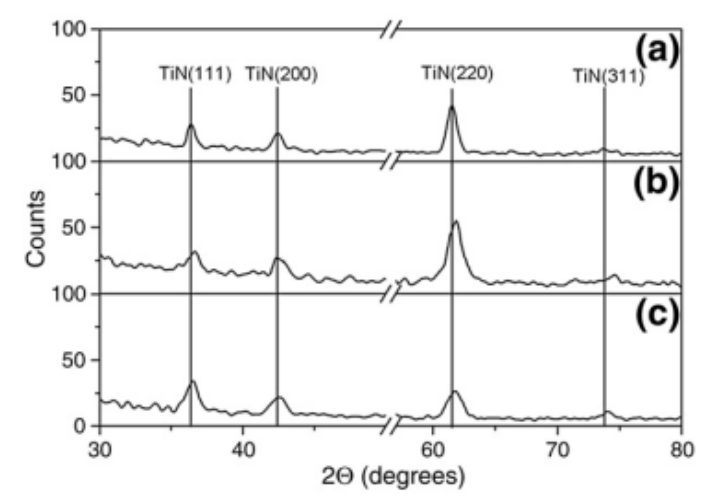

Fig. 4. X-ray diffractorams of TiN films deposited at room temperature: initial deposited layer (a); irradiated at $1 \cdot 10^{15} \mathrm{~cm}^{-2}$ (b), $1 \cdot 10^{16} \mathrm{~cm}^{-2}$ (c) [21].

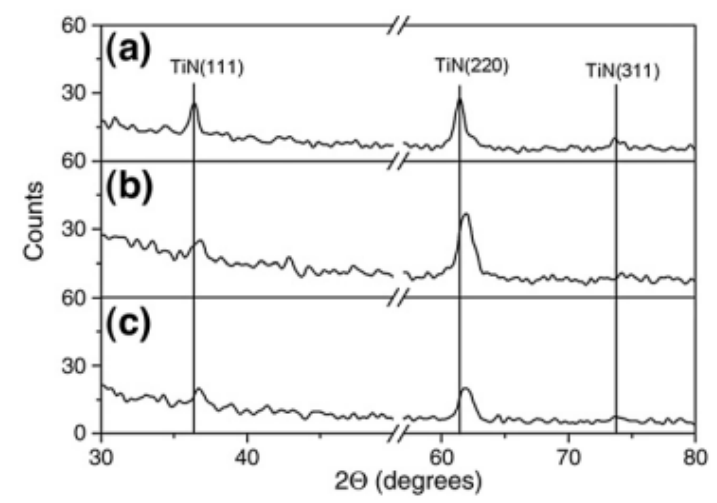

Fig. 5. X-ray diffractorams of TiN films deposited at $150{ }^{\circ} \mathrm{C}$ : initial deposited layer (a); irradiated at $1 \cdot 10^{15} \mathrm{~cm}^{-2}$ (b), $1 \cdot 10^{16} \mathrm{~cm}^{-2}$ (c) [21].
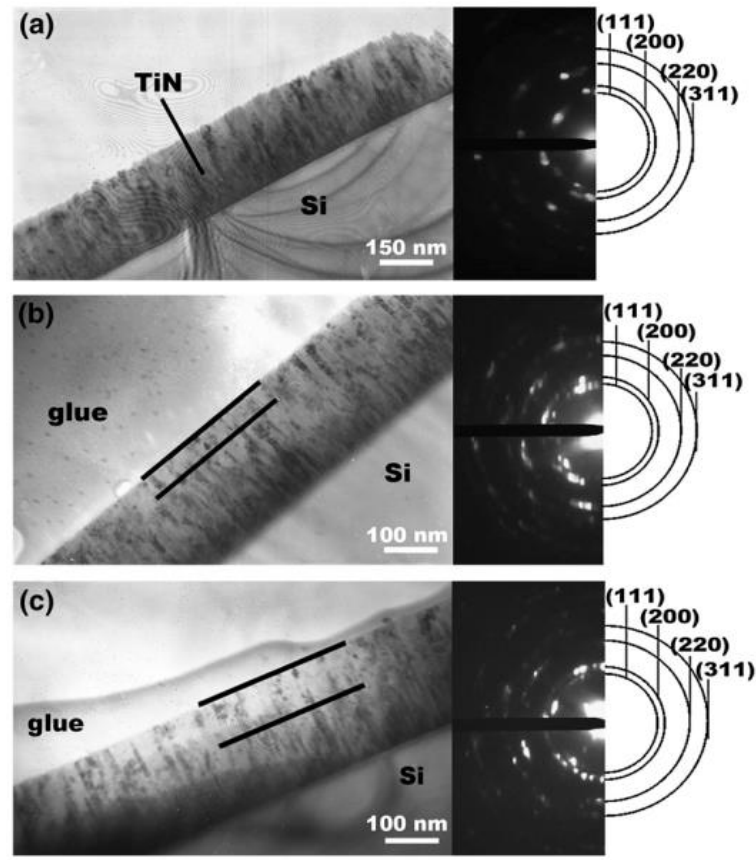

Fig. 6. TEM images and corresponding microdiffraction patterns of TiN/Si structures deposited at $150^{\circ} \mathrm{C}$ before (a) and after irradiation with $\mathrm{Ar}^{+}$ions, fluences $1 \cdot 10^{15} \mathrm{~cm}^{-2}$ (b) and $1 \cdot 10^{16} \mathrm{~cm}^{-2}(\mathrm{c})[21]$.
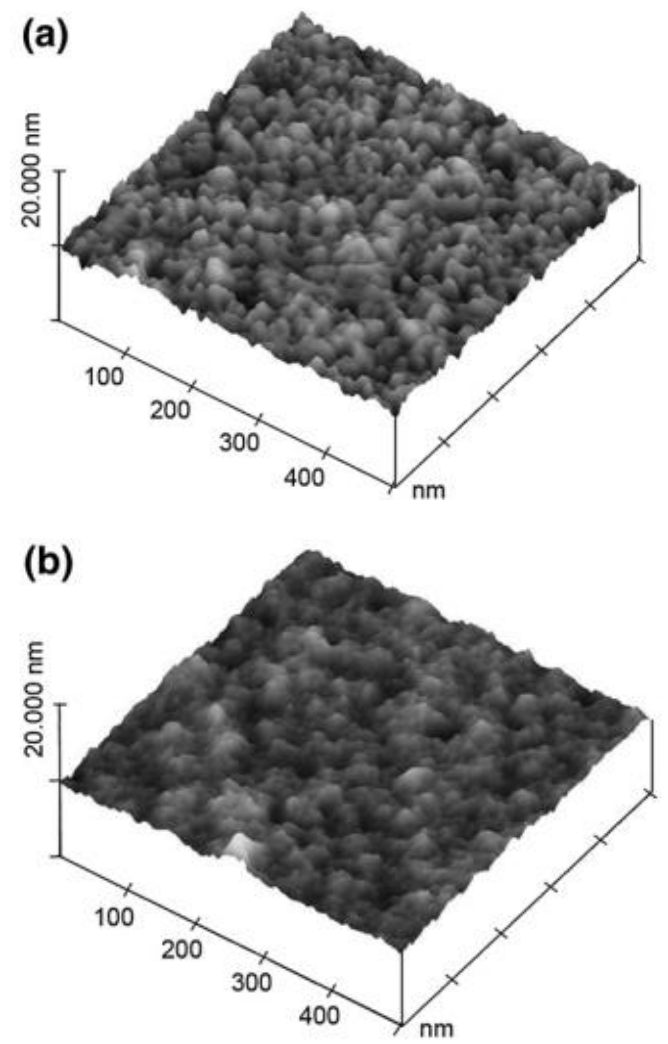

Fig. 7. AFM images of the surface of TiN film deposited on $\mathrm{Si}$ at room temperature before (a) and after irradiation with $\mathrm{Ar}^{+}$ ions $\left(E=120 \mathrm{keV}\right.$, fluences $\left.1 \cdot 10^{16} \mathrm{~cm}^{-2}\right)($ b) $[21]$. 

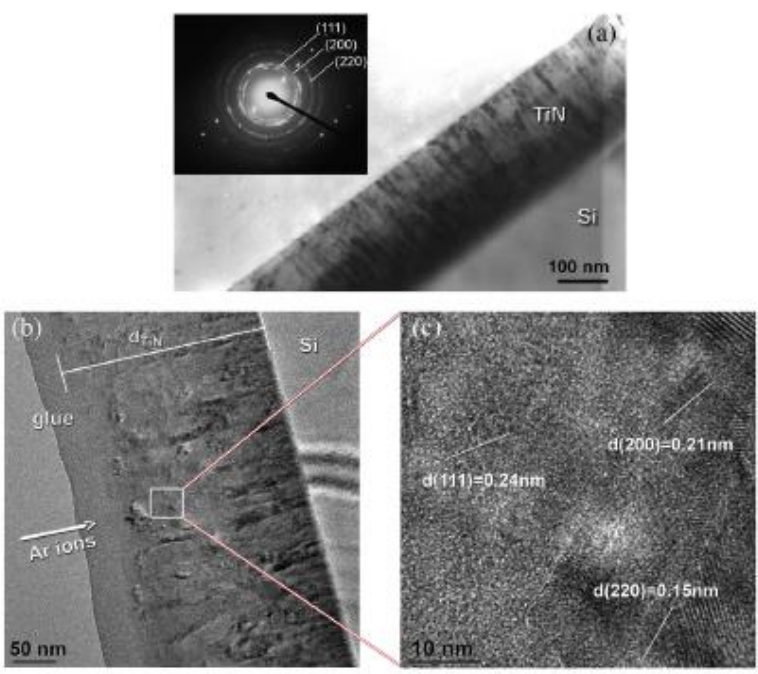

Fig. 8. TEM images and electron diffraction pattern of TiN-Si structure deposited at $150{ }^{\circ} \mathrm{C}$ before (a) and after irradiation with $\mathrm{Ar}^{+}$ions, at the fluence $2 \cdot 10^{16} \mathrm{~cm}^{-2}$ (b); (c) highresolution TEM image of the damaged area (b) [22].

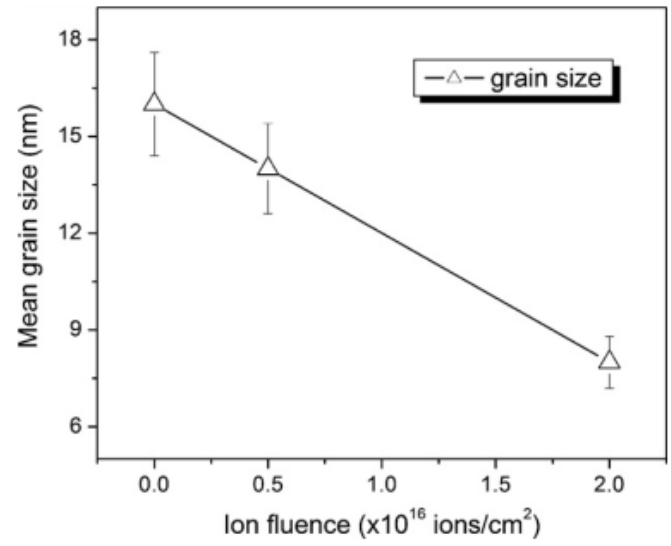

Fig. 9. Change in the average grain size of TiN films depending on the fluence of $\mathrm{Ar}^{+}$ions [23].
The authors [21] also found that irradiation with $\mathrm{Ar}^{+}$ions possessing the energy $120 \mathrm{keV}$ at the fluences $1 \cdot 10^{15} \mathrm{~cm}^{-2}$ and $1.0 \cdot 10^{16} \mathrm{~cm}^{-2}$ of the TiN films with the thickness $\sim 240 \mathrm{~nm}$ and grain sizes 13 to $16 \mathrm{~nm}$ grown on silicon substrates leads to decreasing the lattice constant for TiN from 0.427 down to $0.423 \mathrm{~nm}$ and increasing microdeformation of layers. Here the stoichiometric composition $(\sim 1.0)$ of TiN remains unchanged after irradiation.

In [22], there studied is the comparative effect of irradiation with $E=200 \mathrm{keV}, \mathrm{Ar}^{+}$ions, at the fluences $5 \cdot 10^{15}$ to $2 \cdot 10^{16} \mathrm{~cm}^{-2}$ and that with $E=80 \mathrm{keV}, \mathrm{V}^{+}$ions, at the fluence $2 \cdot 10^{17} \mathrm{~cm}^{-2}$ at room temperature on the TiN films of the thickness $240 \mathrm{~nm}$ prepared using the reactive ion sputtering onto the $\mathrm{Si}(100)$ wafers at $150{ }^{\circ} \mathrm{C}$. TEM studies [22] showed that the initial TiN film has a polycrystalline columnar structure along its full thickness with the (111), (200) and (220) orientations (Fig. 8a). Irradiation with $\mathrm{Ar}^{+}$ions, at the fluence $2 \cdot 10^{16} \mathrm{~cm}^{-2}$ destroys the columnar structure in the upper layer at the thickness close to $160 \mathrm{~nm}$. The residue of the TiN film keeps its structure (Figs. 8b and 8c).

The damaged top layer according to the X-ray diffractogram consists of nanocrystalline grains with the diameter of 7 to $10 \mathrm{~nm}$. The interplanar distances 0.245 , 0.212 and $0.149 \mathrm{~nm}$ correspond to TiN (111), (200) and (220) planes (Fig. 8c), respectively.

As a result of irradiation of TiN film with $\mathrm{V}^{+}$ions, at the fluence $2 \cdot 10^{17} \mathrm{~cm}^{-2}$, it was found that the TiN film consists of amorphous (oxidized) surface layer of 20 to $30 \mathrm{~nm}$ thickness, damaged 120 to $170 \mathrm{~nm}$ thick layer containing $\mathrm{V}$, and the rest TiN sublayer of columnar structure.

The X-ray diffractograms of deposited and ionimplanted TiN films presented in [22] show that, at $36.21^{\circ}$ in the deposited film, the reflection (111) from the cubic phase in polycrystalline $\mathrm{TiN}$ is revealed. It indicates predominance of (111) orientation during growth of the TiN film. The small shift and broadening

Table. Data on the effect of irradiation with different ions on the structure and properties of the TiN films deposited onto silicon wafers [19, 21-23].

\begin{tabular}{|c|c|c|c|c|c|c|}
\hline \multirow[b]{2}{*}{$\begin{array}{l}\text { Object and } \\
\text { references }\end{array}$} & \multirow[b]{2}{*}{$\begin{array}{c}\text { Grain } \\
\text { size, } \mathrm{nm}\end{array}$} & \multicolumn{4}{|c|}{ Irradiation conditions } & \multirow[b]{2}{*}{ Main results } \\
\hline & & Ion & Energy, keV & $\begin{array}{c}\text { Dose, } \\
\text { fluence, } \mathrm{cm}^{-2}\end{array}$ & $T, \mathrm{~K}$ & \\
\hline $\begin{array}{l}\text { TiN film with the } \\
\text { thickness } \\
\sim 100 \mathrm{~nm}[19]\end{array}$ & $8-100$ & $\mathrm{He}^{+}$ & 12,35 & $4 \cdot 10^{16}-10^{17}$ & 293 & $\begin{array}{l}\text { With decreasing grain size the } \\
\text { radiation resistance increases }\end{array}$ \\
\hline $\begin{array}{l}\text { TiN film with the } \\
\text { thickness } \\
\sim 240 \mathrm{~nm} \mathrm{[21]}\end{array}$ & $13-16$ & $\mathrm{Ar}^{+}$ & 35 & $10^{15}-10^{16}$ & 293 & $\begin{array}{l}\text { With increasing fluence the grain } \\
\text { size decreases, microstrains and } \\
\text { dislocation density increase }\end{array}$ \\
\hline $\begin{array}{l}\text { TiN film with the } \\
\text { thickness } \\
\sim 240 \mathrm{~nm} \mathrm{[22]}\end{array}$ & 16 & $\mathrm{~V}^{+}$ & 80 & $2 \cdot 10^{17}$ & 300 & $\begin{array}{l}\text { The reflections from vanadium } \\
\text { nitride } \mathrm{VN} \text { in the amorphous state } \\
\text { without formation of ternary } \\
\text { compounds are observed. }\end{array}$ \\
\hline $\begin{array}{l}\text { TiN film with the } \\
\text { thickness } \\
\sim 240 \mathrm{~nm}[23]\end{array}$ & 16 & $\mathrm{Ar}^{+}$ & 200 & $5 \cdot 10^{15}-2 \cdot 10^{16}$ & 300 & $\begin{array}{l}\text { Grain sizes are reduced down to } \\
8 \mathrm{~nm} \text {, while the average balance } \\
\text { of } \mathrm{N} \text { :Ti atoms is kept uncharged. }\end{array}$ \\
\hline
\end{tabular}


the peak of $\mathrm{TiN}$ (111) are observed after implantation of $\mathrm{Ar}^{+}$ions. It is assumed that the reason for these changes is reduced content of nitrogen after ion-induced rupture of $\mathrm{Ti} / \mathrm{N}$ bonds. It decreases the size of the crystallites, which has practically no effect on the average balance of $\mathrm{N}: \mathrm{Ti}$ atoms in the damaged area.

The results obtained by the authors [21-23] have shown that irradiation with $\mathrm{Ar}^{+}$ions leads to formation of small crystallites (Table), the size of which decreases with increasing the fluence (Fig. 9). This is because the defects appear after irradiation and destroy the columnar structure of TiN film.

In [24] the authors carried out comparative studies of the effect for reactive sputtering methods - the method of ion implantation (II) as well as the method of condensation and ion bombardment (CIB) - on the growth mechanism and the phase composition of the TiN films obtained on the single-crystal Si wafers. The target in both methods was titanium plate, and the reactive gas - nitrogen. The results showed that the II method leads to significantly higher ( 1.7\%) compression of the substrate than the CIB method $(\sim 1.1 \%)$. In the II method, the diffraction patterns, in addition to the lines of $\mathrm{Si}$, Ti-Si, contain the lines of slightly textured nitride $\mathrm{Si}_{3} \mathrm{~N}_{4}$, which are not seen in the diffraction patterns in the CIB method. Besides, as in the CIB method, from the outside coating, the islands of $\mathrm{SiO}_{2}$ oxide in the crystalline and amorphous forms are formed. It is found that the TiN films obtained by the II method are multiphase, and those obtained using the CIB method are diphase and consist of titanium nitride and titanium oxide. The silicon substrate in the initial period of film formation is intensively sputtered, and then the process of implantation of $\mathrm{Ti}, \mathrm{N}_{2}$ and $\mathrm{O}_{2}$ ions dominates over emission of atoms from the substrate. Emerging nitrides creates a diffusion barrier for $\mathrm{O}_{2}$ atoms, so oxides arise on the outer surface of the films. The TiN films obtained by the II method contain nitrides and oxides of $\mathrm{Si}$ atoms, as well as nitride and oxide of titanium $\left(\mathrm{TiN}, \mathrm{TiO}_{2}\right)$. Similar comparative studies were performed by the authors [25].

\section{Conclusions}

These data show that the TiN films are effective materials when they are used in the systems of contact metallization as diffusion barriers in silicon semiconductor device technology. It is important to note the desirability of further comprehensive studies for the mechanisms of radiation resistance of diffusion barriers based on nanostructured TiN films.

\section{References}

1. R.A. Andrievskii, Preparation and properties of nanocrystalline refractory compounds // Uspekhi khimii, 23(5), p. 431-446 (1994), in Russian.
2. R.A. Andrievskii, Synthesis and properties of interstitial phases films // Uspekhi khimii, 66(1), p. 57-77 (1997), in Russian.

3. A.I. Gusev, Effects of nanocrystalline state in compact metals and its compounds // Uspekhi fiz. nauk, 168(1), p. 55-83 (1998), in Russian.

4. H. Gleiter, Nanostructured materials: basic concepts and microstructure // Acta Materialia, 48(1), p. 1-29 (2000), in Russian.

5. R.A. Andrievskii, Thermal stability of nanomaterials // Uspekhi khimii, 71(10), p. 968-981 (2002), in Russian.

6. P.I. Ignatenko, O.A. Goncharov, M.A. Muza, Yu.V. Kudelin, Synthesis, phase formation, structure and properties of the films prepared by sputtering // Fizika, khimiya tverdogo tila, 5(4), p. 701-708 (2004), in Ukrainian.

7. V.M. Beresnev, A.D. Pogrebnyak, N.A. Azarenkov, V.I. Farenik, G.V. Kirik, Nanocrystalline and nanocomposite coatings, structure, properties // Phys. Surf. Eng. (Khar'kov), 5(1-2), p. 4-27 (2007), in Russian.

8. A.D. Pogrebnyak, A.P. Shpak, N.A. Azarenkov, V.M. Beresnev, Structure and properties of hard and superhard nanocomposite coatings // Uspekhi fiz. nauk, 179(1), p. 35-64 (2009), in Russian.

9. M.-A. Nicolet, Diffusion barriers in thin films // Thin Solid Films, 52, p. $415-443$ (1978).

10. P.S. Ho, General aspects of barrier layers for verylarge-scale integration applications. I: Concepts // Thin Solid Films, 96(4), p. 301-306 (1982).

11. L.A. Seidman, Reactively sputtering in vacuum of titanium nitride layers and using them in the systems of contact metallization of semiconductor devices // Obsory po elektronnoi tekhnike. Poluprovodnikovye pribory, 6(1366), p. 1-58 (1988), in Russian.

12. O.A. Ageev, A.E. Belyaev, N.S. Boltovets, R.V. Konakova, V.V. Milenin, V.A. Pilipenko, Interstitial Phases in Technology of Semiconductor Devices and VLSI Circuits. Institute for Single Crystals, Khar'kov, 2008 (in Russian).

13. S.K. Rha, W.J. Lee, S.Y. Lee, Y.S. Hwang et al., Improved TiN film as a diffusion barrier between copper and silicon // Thin Solid Films, 320(1), p. 134-140 (1998).

14. A. Alberti, S. Molinaro, F. La Via, C. Bongiorno, G. Ceriola, S. Ravesi, Correlation between microstructure control, density and diffusion barrier properties of $\mathrm{TiN}(\mathrm{O})$ films // Microelectron. Eng. 60, p. 81-87 (2002).

15. Y.H. Shin, Y. Shimogaki, Diffusion barrier property of $\mathrm{TiN}$ and $\mathrm{TiN} / \mathrm{Al} / \mathrm{TiN}$ films deposited with FMCVD for $\mathrm{Cu}$ interconnection in ULSI // Sci. and Technol. Adv. Mater. 5, p. 399-405 (2004).

16. W.H. Lee, Y.L. Kuo, H.J. Huang, C. Lee, Effect of density on the diffusion barrier property of $\mathrm{TiN}_{\mathrm{x}}$ films between $\mathrm{Cu}$ and $\mathrm{Si} / /$ Materials Chem. and Phys. 85, p. 444-449 (2004). 
17. R.A. Andrievskii, Radiation stability of nanomaterials // Nanotechnologies in Russia, 6 (5-6), p. 357-369 (2011).

18. R.A. Andrievskii, Effects of irradiation on properties of nanomaterials // Fizika metallov metallovedenie, 110(3), p. 243-254 (2010), in Russian.

19. H. Wang, R. Araujo, J.G. Swadener, Y.Q. Wang, X. Zhang, E.G. Fu, T. Cagin, Ion irradiation effects in nanocrystalline TiN coatings // Nucl. Instrum. and Meth. in Phys. Res. B, 261, p. 1162-1166 (2007).

20. P.C. Millett, D.S. Aidhy, T. Desai, S.R. Phillpot, D. Wolf, Grain-boundary source/sink behavior for point defects: an atomistic simulation study // Int. J. Mater. Res. 100, p. 550-555 (2009).

21. M. Popović, M. Novaković, N. Bibić, Structural characterization of TiN coatings on $\mathrm{Si}$ substrates irradiated with $\mathrm{Ar}$ ions // Materials Characterization, 60, p. 1463-1470 (2009).
22. M. Popović, M. Novaković, A. Traverse, K. Zhang, N. Bibić, H. Hofsäss, K.P. Lieb, Modifications of reactively sputtered titanium nitride films by argon and vanadium ion implantation: Microstructural and opto-electric properties // Thin Solid Films, 531, p. 189-196 (2013).

23. M. Popović, M. Novaković, M. Šiljegovic, N. Bibić, Effects of $200 \mathrm{keV}$ argon ions irradiation on microstructural properties of titanium nitride films // Nucl. Instrum. and Meth. in Phys. Res. B, 279, p. 144-146 (2012).

24. N.A. Vasilenko, I.G. Kostenko, Comparison of the phase composition and structure of nitride films prepared by different methods of reactive sputtering // Nauchnyi vestnik DGMA, 1(9 E), p. 41-45 (2012), in Russian.

25. M. Bonelli, L.A. Guzman, A. Miotello, L. Calliari, M. Elena, P.M. Ossi, Structure and optical properties of TiN films prepared by dc sputtering and by ion beam assisted deposition // Vacuum, 43(5-7), p. 459-462 (1992). 